\title{
Supporting Information for: Voxel-scale Conversion Mapping Informs Intrinsic Resolution in Stereolithographic Additive Manufacturing
}

Tobin E. Brown ${ }^{1+}$, Veruska Malavé ${ }^{\dagger}{ }^{+}$, Callie I. Higgins ${ }^{1}$, Anthony P. Kotula ${ }^{2}$, Benjamin W. Caplins ${ }^{1}$, Edward J. Garboczi $^{1}$, Jason P. Killgore ${ }^{1 *}$

${ }^{1}$ Applied Chemicals and Materials Division, National Institute of Standards and Technology, Boulder, CO, USA

2 Materials Science and Engineering Division, National Institute of Standards and Technology, Gaithersburg, MD, USA

*email: Jason.killgore@nist.gov

Materials: Pentaerythritol tetrakis mercaptopropionate (PETMP), tri(ethylene glycol) divinyl ether (TEGDVE), trimethylolpropane triacrylate (TMPTA), diphenyl(2,4,6-trimethylbenzoyl)phosphine oxide (TPO), and N,N, $N^{\prime}, N^{\prime}$-tetramethylethylenediamine (TEMED) were purchased from Sigma Aldrich and used without further purification. Viscosity standards N100, N350, and S2000 were purchased from Cannon Instrument Company and used as received.

Stokes' solution for an infinite cylinder oscillating in an infinite fluid $\left(d_{\text {eff }}\right)$ :

For small probes, the Stokes' solution for fluid flow, empirically modified for size effects, predicts that a cylinder interacts with a volume of fluid near the probe with a thickness $\delta_{\text {eff }}$ given by de Baubigny et al.: ${ }^{[1]}$

$\frac{\delta_{e f f}}{\delta}=-\frac{R}{\delta}+\sqrt{\left(\frac{R}{\delta}\right)^{2}+2 \frac{R}{\delta}\left(g_{1}\left(\frac{R}{\delta}\right)-g_{2}\left(\frac{R}{\delta}\right)\right)}$

where $R$ is the probe radius, $\delta=\sqrt{\frac{\eta}{\rho \pi f}}$ is the viscous layer thickness in the two-dimensional Stokes' solution (i.e. an oscillating wall), liquid viscosity $\eta$, density $\rho$, oscillation frequency $f, g_{1}$ and $g_{2}$ the real and imaginary parts, respectively, of the function $g(x)=\frac{K_{1}[(1-i) x]}{K_{0}[(1-i) x]}$, where $K_{n}$ denotes the modified Bessel function of the second kind of order $n$. This equation simplifies for $R \ll \delta$ to: ${ }^{[1]}$

$\frac{\delta_{\text {eff }}}{\delta}=-\frac{R}{\delta}+\sqrt{\left(\frac{R}{\delta}\right)^{2}+\frac{\pi}{2\left[\ln \left(\frac{R}{\delta}\right)\right]^{2}}}$

Equation S2 shows the confinement of the viscous layer due to small radius probes, as well as the ability to increase the resolution through operation at high oscillation frequencies. 
Table S1: Fluid properties for viscosity standards and resins

\begin{tabular}{|c|c|c|c|}
\hline Fluid & Source & $\begin{array}{l}\text { Viscosity [mPa s] @ } 25 \\
{ }^{\circ} \mathrm{C}\end{array}$ & $\begin{array}{l}\text { Density }\left[\mathrm{kg} \mathrm{m}^{-3}\right] @ 25 \\
{ }^{\circ} \mathrm{C}\end{array}$ \\
\hline $\begin{array}{l}\text { N100 (viscosity } \\
\text { standard 1) }\end{array}$ & $\begin{array}{l}\text { Cannon } \\
\text { Instrument Co. }\end{array}$ & $202^{a}$ & $879^{a}$ \\
\hline $\begin{array}{l}\text { N350 (viscosity } \\
\text { standard 2) }\end{array}$ & $\begin{array}{l}\text { Cannon } \\
\text { Instrument Co. }\end{array}$ & $600^{a}$ & $840^{a}$ \\
\hline $\begin{array}{l}\text { S2000 (viscosity } \\
\text { standard 3) }\end{array}$ & $\begin{array}{l}\text { Cannon } \\
\text { Instrument Co. }\end{array}$ & $4700^{a}$ & $874^{a}$ \\
\hline Thiol-ene resin & $\begin{array}{l}\text { Mixture - see } \\
\text { methods }\end{array}$ & $21^{b}$ & $1100^{c}$ \\
\hline $\begin{array}{l}\text { 1,6-Hexanediol } \\
\text { diacrylate }\end{array}$ & Sartomer & $9^{a}$ & $1020^{\mathrm{a}}$ \\
\hline $\begin{array}{l}\text { Tri(ethylene glycol) } \\
\text { dimethacrylate }\end{array}$ & Sartomer & $11^{\mathrm{a}}$ & $1070^{a}$ \\
\hline $\begin{array}{l}\text { Poly(ethylene glycol) } \\
\text { diacrylate, } 600 \mathrm{~g} / \mathrm{mol}\end{array}$ & Sartomer & $90^{a}$ & $1100^{\mathrm{a}}$ \\
\hline $\begin{array}{l}\text { Pentaerythritol } \\
\text { tetraacrylate }\end{array}$ & Sartomer & $352^{a}$ & $1179^{e}$ \\
\hline $\begin{array}{l}\text { Di(trimethylol } \\
\text { propane) } \\
\text { tetraacrylate }\end{array}$ & Sartomer & $600^{a}$ & $1010^{\mathrm{a}}$ \\
\hline $\begin{array}{l}\text { Epoxy acrylate } \\
\text { oligomer (CN110) }\end{array}$ & Sartomer & $3000^{a}$ & $1174^{\mathrm{a}}$ \\
\hline
\end{tabular}

a From supplier, ${ }^{b}$ Measured, ${ }^{c}$ Weighted average of PETMP and TEGDVE 
Table S2: Drag Forces for an oscillating cylinder from experiment and modeling

\begin{tabular}{|c|c|c|c|c|c|c|c|c|c|}
\hline \multirow[b]{2}{*}{$\begin{array}{l}L^{\prime}(L) \\
{[\mathrm{nm}]}\end{array}$} & \multirow[b]{2}{*}{$\begin{array}{l}\text { Fluid name } \\
\text { (viscosity) }\end{array}$} & \multicolumn{4}{|c|}{$f=50 \mathrm{kHz}$} & \multicolumn{4}{|c|}{$f=300 \mathrm{kHz}$} \\
\hline & & $\begin{array}{l}F_{\mathrm{d}, \mathrm{a}} \\
{[\mathrm{nm}]}\end{array}$ & $\begin{array}{l}\mathbf{F}_{\mathrm{d}, \mathrm{b}} \\
{[\mathrm{nm}]}\end{array}$ & $\begin{array}{l}F_{\mathrm{d}, \mathrm{c}} \\
{[\mathrm{nm}]}\end{array}$ & $\begin{array}{l}F_{\mathrm{d}, \mathrm{d}} \\
{[\mathrm{nm}]}\end{array}$ & $\begin{array}{l}\mathbf{F}_{\mathrm{d}, \mathrm{a}} \\
{[\mathrm{nm}]}\end{array}$ & $\begin{array}{l}F_{\mathrm{d}, \mathrm{b}} \\
{[\mathrm{nm}]}\end{array}$ & $\begin{array}{l}F_{\mathrm{d}, \mathrm{c}} \\
{[\mathrm{nm}]}\end{array}$ & $\begin{array}{l}\mathbf{F}_{\mathrm{d}, \mathrm{d}} \\
{[\mathrm{nm}]}\end{array}$ \\
\hline \multirow{3}{*}{$\begin{array}{l}600 \\
(820)\end{array}$} & $\begin{array}{l}\text { N100 } \\
\text { (202 mPa s) }\end{array}$ & 0.58 & 0.88 & 0.91 & 0.25 & 2.90 & 6.3 & 5.45 & 1.76 \\
\hline & $\begin{array}{l}\text { N350 } \\
(600 \mathrm{mPa} \mathrm{s})\end{array}$ & 1.55 & 2.7 & 2.7 & 0.69 & 6.25 & 19 & 16.18 & 4.75 \\
\hline & $\begin{array}{l}\mathrm{S} 2000 \\
(4700 \mathrm{mPa} \mathrm{s})\end{array}$ & 13.27 & 20 & 21.13 & 4.73 & 34.48 & 149 & 126.79 & 31.97 \\
\hline \multirow{3}{*}{$\begin{array}{l}1200 \\
(1420)\end{array}$} & $\begin{array}{l}\text { N100 } \\
\text { (202 mPa s) }\end{array}$ & 0.80 & 1.47 & 1.19 & 0.44 & 3.73 & 10.2 & 7.23 & 3.05 \\
\hline & $\begin{array}{l}\text { N350 } \\
(600 \mathrm{mPa} \mathrm{s})\end{array}$ & 2.10 & 4.5 & 3.58 & 1.20 & 8.42 & 30 & 21.48 & 8.23 \\
\hline & $\begin{array}{l}\mathrm{S} 2000 \\
(4700 \mathrm{mPa} \mathrm{s})\end{array}$ & 15.08 & 32 & 28.04 & 8.20 & 48.19 & 258 & 168.22 & 55.37 \\
\hline
\end{tabular}

$\mathrm{F}_{\mathrm{d}, \mathrm{a}}$ : Experimentally measured drag force, corrected to $5 \mathrm{~nm}$ amplitude

$\mathrm{F}_{\mathrm{d}, \mathrm{b}}$ : Drag force calculated from computational fluid dynamics (CFD) modeling

$F_{d, c}$ : Drag force calculated using the method of Broersma ${ }^{[2]}$

$F_{d, d}$ : Drag force calculated from Stokes' solution on a cylinder 

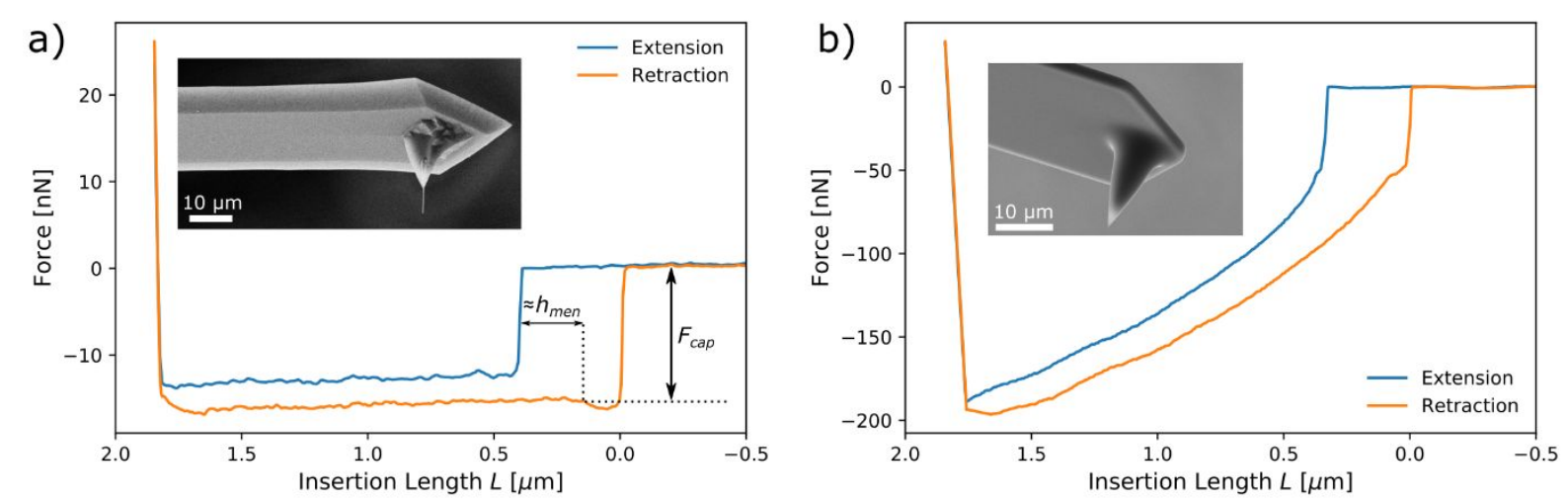

Supplemental Figure S1: Cylindrical AFM probes provide a constant contact line during insertion into liquids. a) Nanocylindrical-tipped AFM probe experiences a constant capillary force $\left(F_{c a p}\right)$ during a force versus distance curve as it transverses the liquid and contacts the solid surface beneath. The meniscus height $\left(h_{m e n}\right)$ can also be estimated from the curve. Inset: scanning electron micrograph of the cantilever. b) In contrast, the meniscus force on a conical AFM probe continues to grow as the probe is moved further into the liquid due to the increasing cross-sectional area of the cone. This behavior is also typical of pyramidal probes. Inset: scanning electron micrograph of the cantilever, scale bars $10 \mu \mathrm{m}$. 


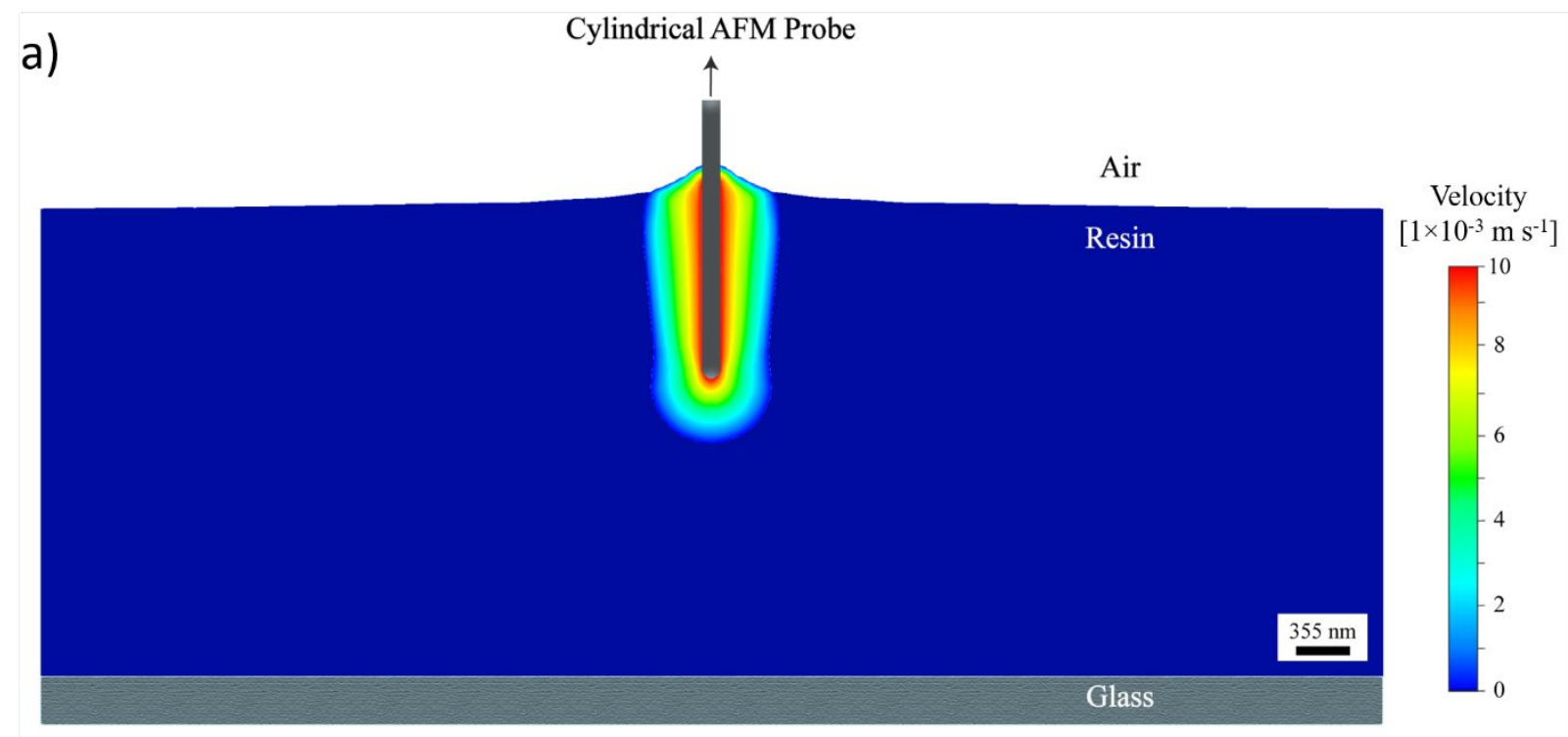

b)
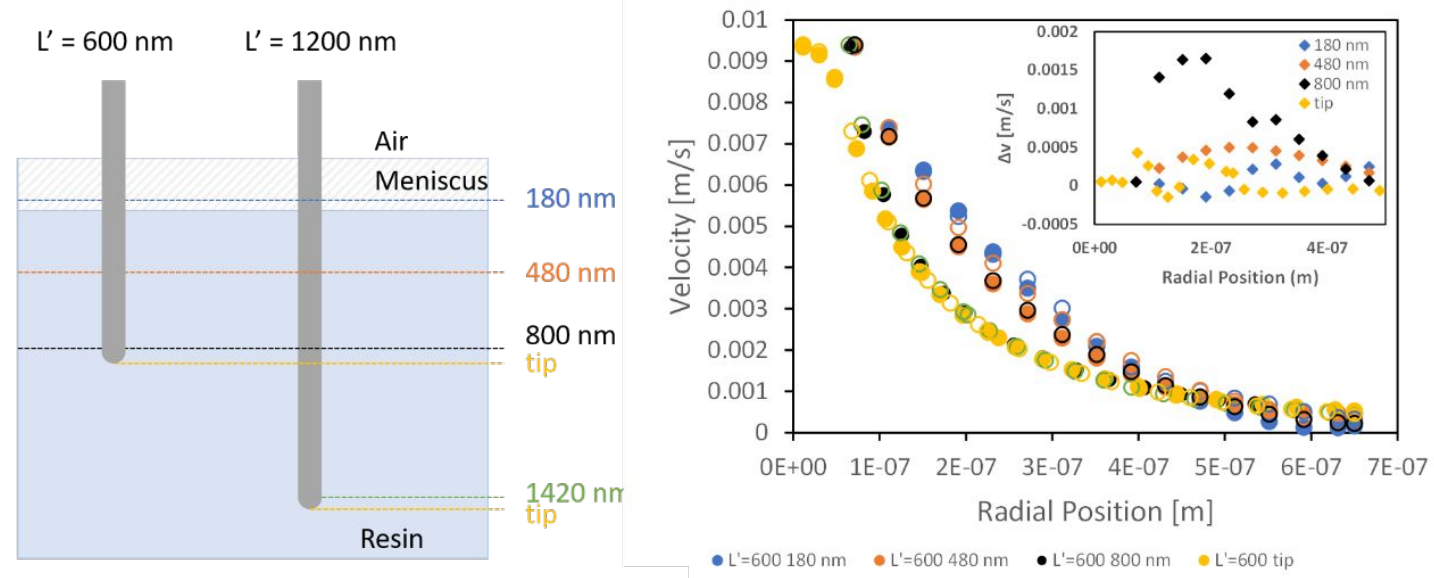

$\circ L^{\prime}=1200180 \mathrm{~nm} \quad \circ L^{\prime}=1200480 \mathrm{~nm} \quad$ O L' $L^{\prime}=1200800 \mathrm{~nm} \quad \circ L^{\prime}=1200$ tip $\quad \circ L^{\prime}=12001420 \mathrm{~nm}$

Supplemental Figure S2: Computational fluid dynamics (CFD) modeling provides insight into the effect of insertion length and position along the probe on the viscous layer thickness. a) Example velocity field showing the full extent of the simulation with $\eta=202 \mathrm{mPa} \cdot \mathrm{s}, L^{\prime}=1200 \mathrm{~nm}, f=300 \mathrm{kHz}$. b) Radial velocity profiles along the probe's depth for $L^{\prime}=600 \mathrm{~nm}$ and $L^{\prime}=1200 \mathrm{~nm}(\eta=202 \mathrm{mPa} \cdot \mathrm{s}, f=300 \mathrm{kHz})$. Inset: $\Delta v=\left.v\right|_{L^{\prime}=1200 \mathrm{~nm}}-\left.v\right|_{L^{\prime}=600 \mathrm{~nm}}$ shows the effect of the relative depth along the probe. Both profiles show a constriction along the probe towards the lower end. The radial profiles for the different insertion lengths are similar $(\Delta v \approx 0)$ near the top surface $(180 \mathrm{~nm})$ and at their respective tips. At 800 $\mathrm{nm}$ depth, which is near the probe tip for $L^{\prime}=600 \mathrm{~nm}$, there exists an envelope where $\Delta v>0$, i.e. the profile is wider near the middle of the probe at $L^{\prime}=1200 \mathrm{~nm}$. 
a)

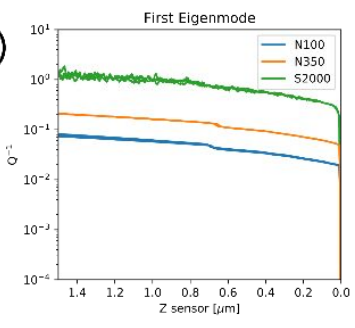

c)

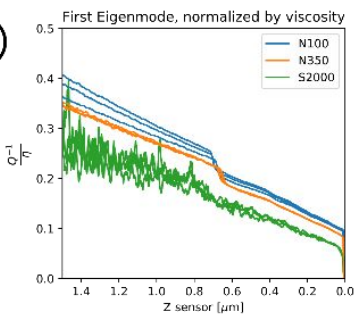

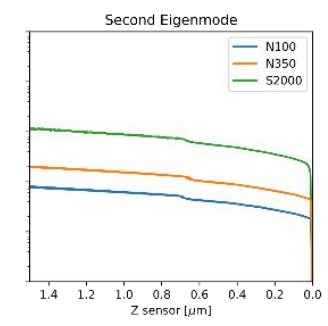
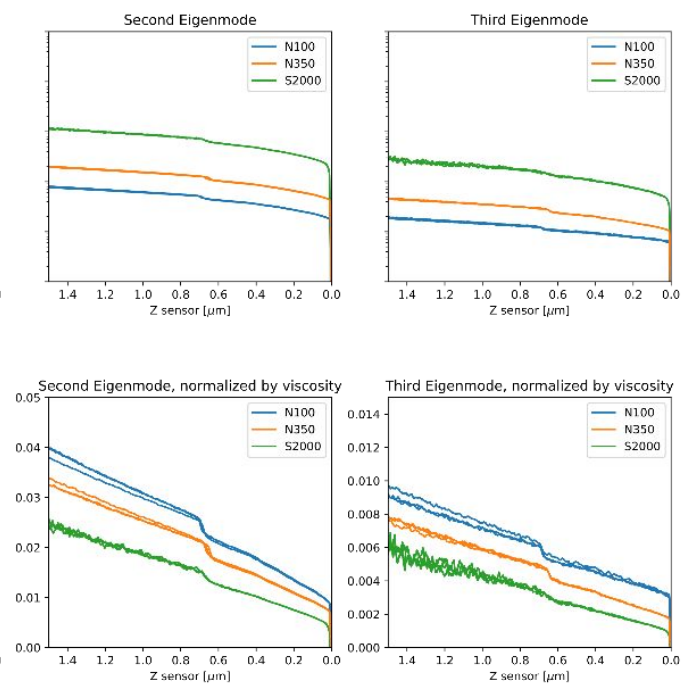

b)
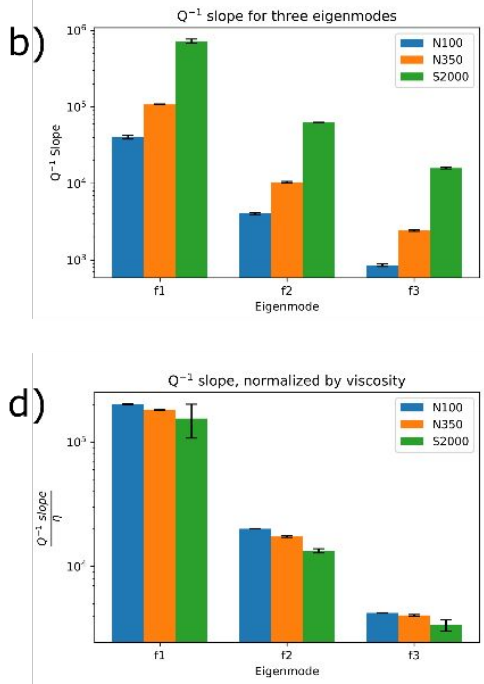

Supplemental Figure S3: AFM experimental results with standard viscosity fluids. a) Measured $Q^{-1}$ values during DART force curves as a function of insertion length $L$ for three test liquids (N100, N350, and S2000) and three cantilever eigenmodes $\left(f_{1}, f_{2}\right.$, and $\left.f_{3}\right)$. For $Q^{-1}$ values approaching 1 , high noise levels can be seen. b) Bar chart of damping slope $\mathrm{d} Q^{-1} / \mathrm{d} L$ versus eigenmode for three test fluids. c) Damping values $Q^{-1}$ normalized by the respective viscosities of the three liquids. $d$ ) Viscosity normalized slopes $\left(\mathrm{d} Q^{-1} / \mathrm{d} L\right) \eta^{-1}$ are approximately equal for the three fluids.
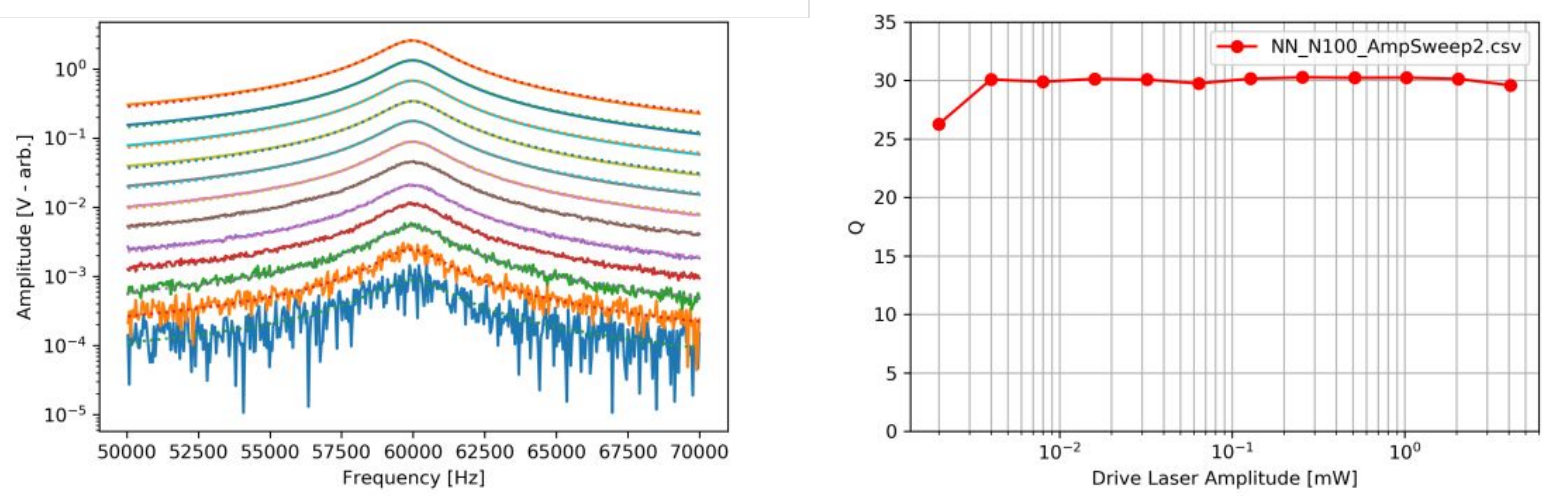

Supplemental figure S4: Resonance peak quality factor $Q$ is not a function of drive amplitude above the noise floor. a) Amplitude versus frequency spectra acquired at varying photothermal drive laser modulation amplitude from $0.02 \mathrm{~mW}$ to $4 \mathrm{~mW}$. Each peak is fit to a damped harmonic oscillator model (dashed line). b) Quality factor $Q$ from the fitting routine plotted versus drive laser amplitude shows no dependence on drive amplitude over two orders of magnitude above the lowest setting $(0.02 \mathrm{~mW})$ 


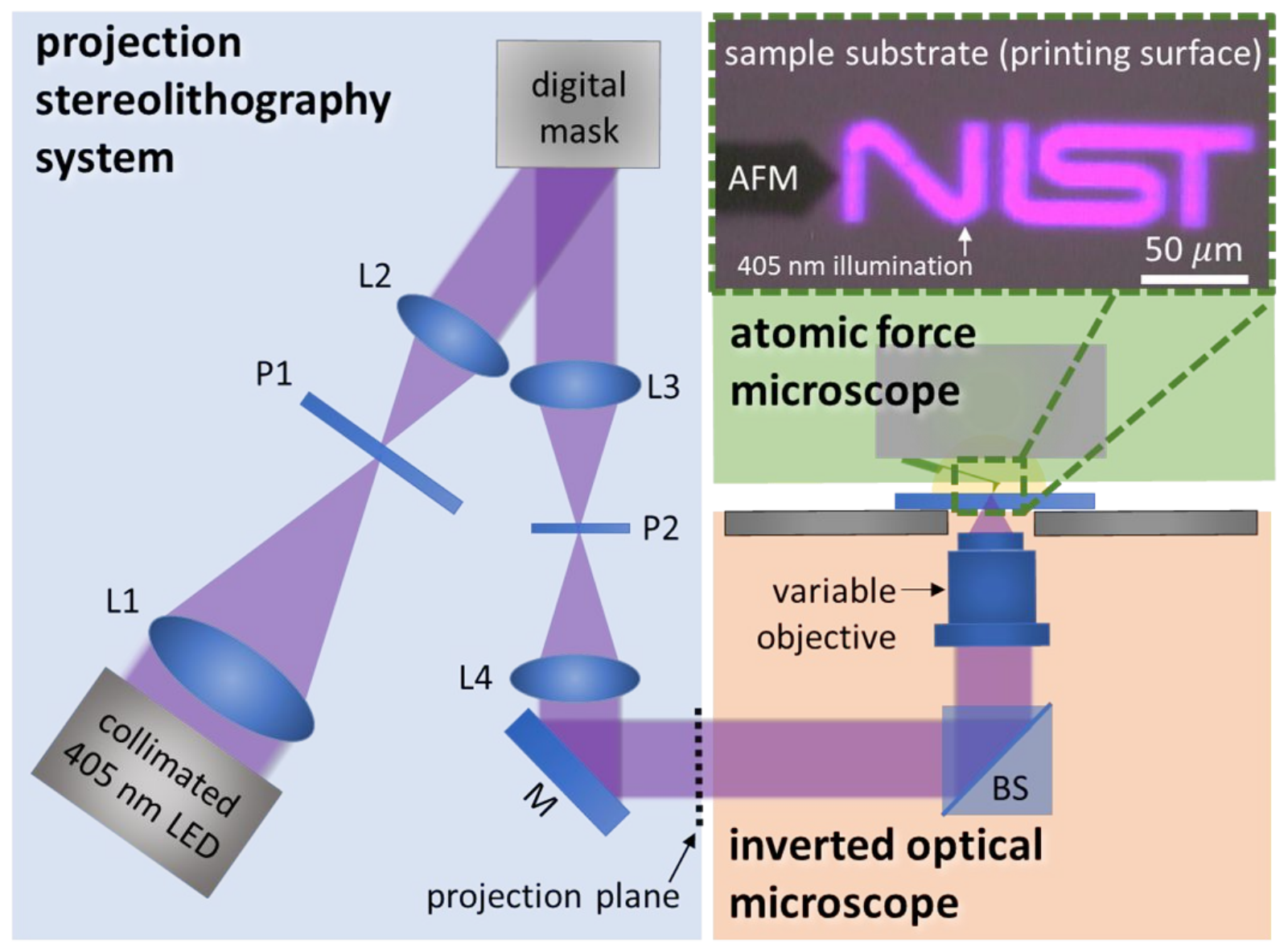

Supplementary Figure S5: A custom-built atomic force microscope (AFM) 3D printer allows in situ measurements of localized photopolymerization. The blue region on the left designates the digital light processing projection optics ( $\mathrm{L}=$ lens, $\mathrm{P}=$ polarizer, $\mathrm{M}=$ mirror, $\mathrm{BS}=$ beam splitter), the orange region is the inverted optical microscope, and green represents the AFM. On the top right is a micrograph of a projected image of the NIST logo showing the AFM cantilever. 

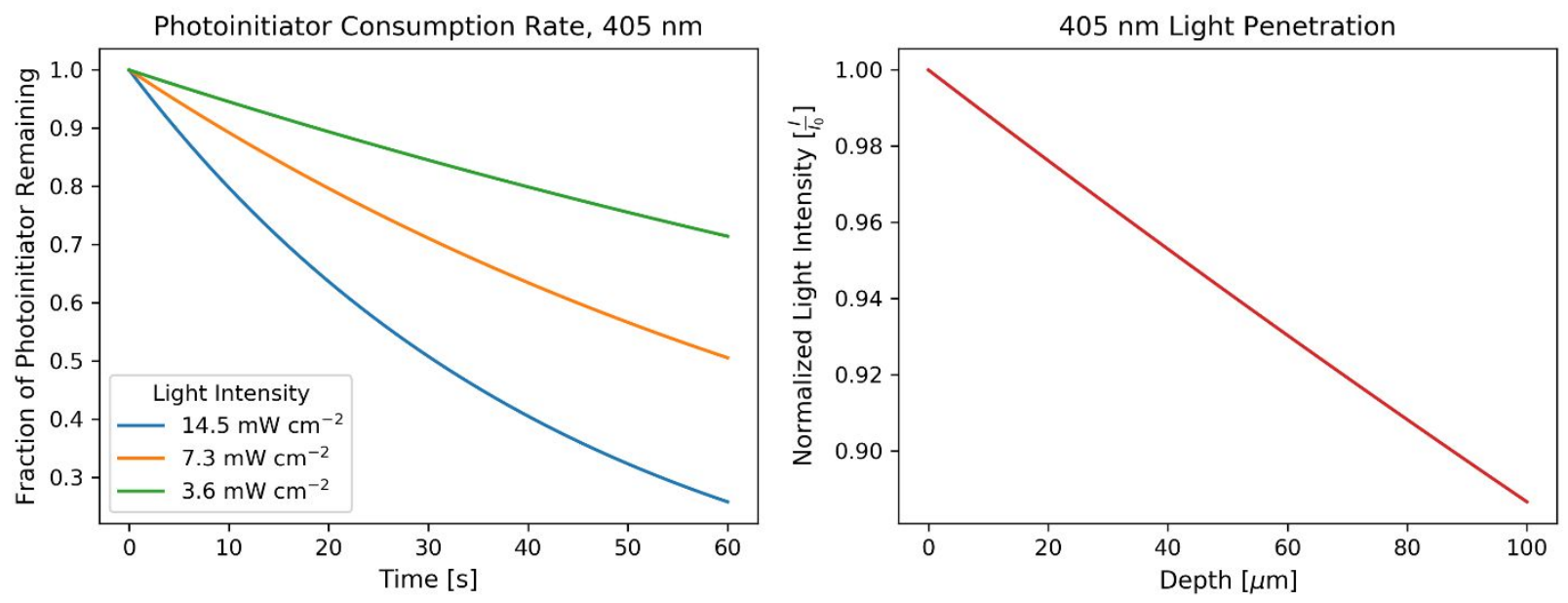

Supplemental Figure S6: Calculated photoinitiator (TPO) consumption (left) and $405 \mathrm{~nm}$ light absorption with 1 wt \% TPO (right). Photoinitiator concentration [TPO] is calculated as:

$[T P O]=[T P O]_{0} e^{-k t}$

with rate constant $k$ :

$k=\frac{\phi \varepsilon \ln (10) I}{N_{A} h v}$

where $\phi$ is the quantum yield of photoinitiator dissociation (assumed unity), $\varepsilon$ is the molar absorptivity $\left(200 \mathrm{~L} \mathrm{~mol}^{-1} \mathrm{~cm}^{-1}\right), l$ is the light intensity, $N_{A}$ is Avogadro's number, $h$ Planck's constant, and $v$ the frequency of light. The light absorption profile is calculate using the Beer-Lambert law:

$\frac{I}{I_{0}}=10^{-\varepsilon c d}$

with concentration $c$ and depth $d$. 

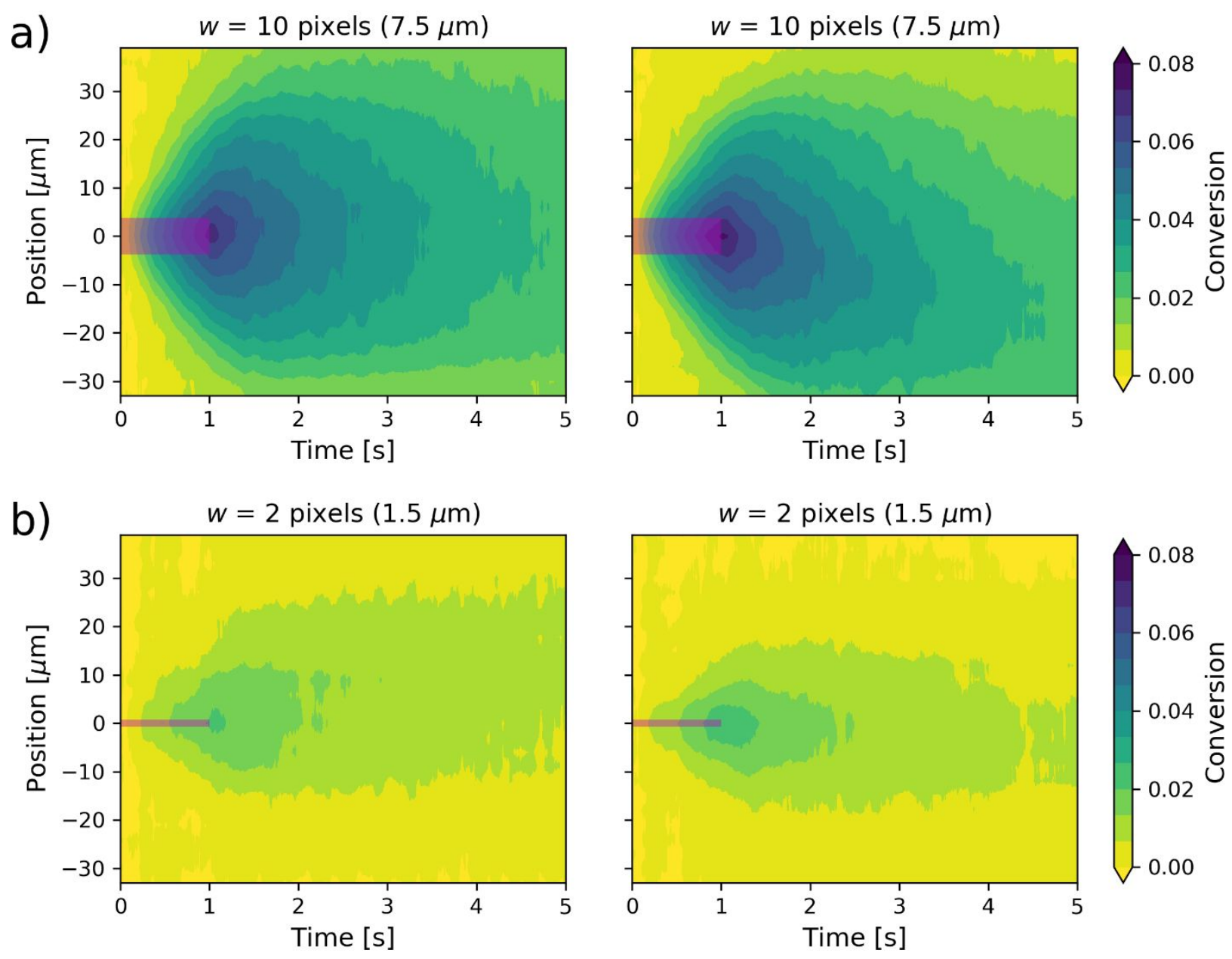

Supplemental Figure S7: Repeated measurements under the same conditions in the same location show similar spatial evolution of the conversion profile due to the reversible nature of the reaction. a) 10 pixel linewidth exposure for $1 \mathrm{~s}$ at $14.5 \mathrm{~mW} \mathrm{~cm}^{-2}$ and (b) 2 pixel linewidth exposure for $1 \mathrm{~s}$ at $14.5 \mathrm{~mW} \mathrm{~cm}^{-2}$. 


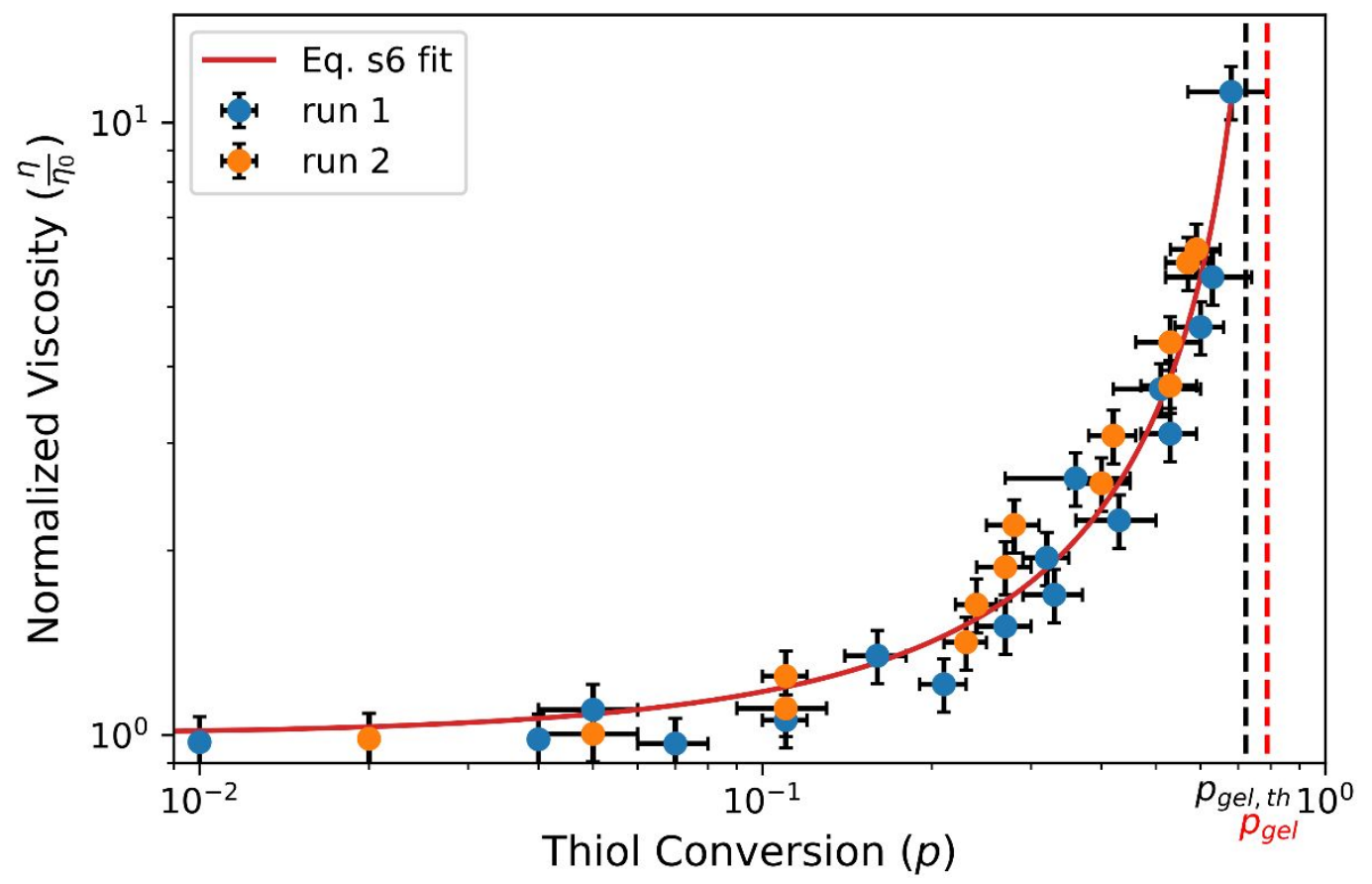

Supplemental Figure S8: Rheo-Raman spectroscopy enables direct correlation between resin viscosity and conversion to inform the localized SCRPR measurement. Viscosity and thiol conversion are measured simultaneously during photopolymerization of the thiol-ene resin and the measurands are fit according to Equation S6:

$\eta=\eta_{0}\left(1-\frac{p}{p_{g e l}}\right)^{-\alpha}$

The theoretical gel point $p_{\text {gel,th }}$ is shown as a black dashed line and calculated from:

$p_{g e l, t h}=\frac{1}{\sqrt{r\left(f_{a}-1\right)\left(f_{b}-1\right)}}$

Where $f_{a}$ and $f_{b}$ are the functionalities of the two monomers, and $r$ is the stoichiometric ratio. In the thiol-ene resin, $f_{a}=4, f_{b}=2, r=0.64$, and $p_{\text {gel, th }}=0.72$. The measured gel point $\left(p_{\text {gell }}, 0.79\right)$ is shown as a red dashed line. Two independent trials are shown. Error bars represent standard error of the thiol peak area and an estimated error of $10 \%$ of viscosity. 


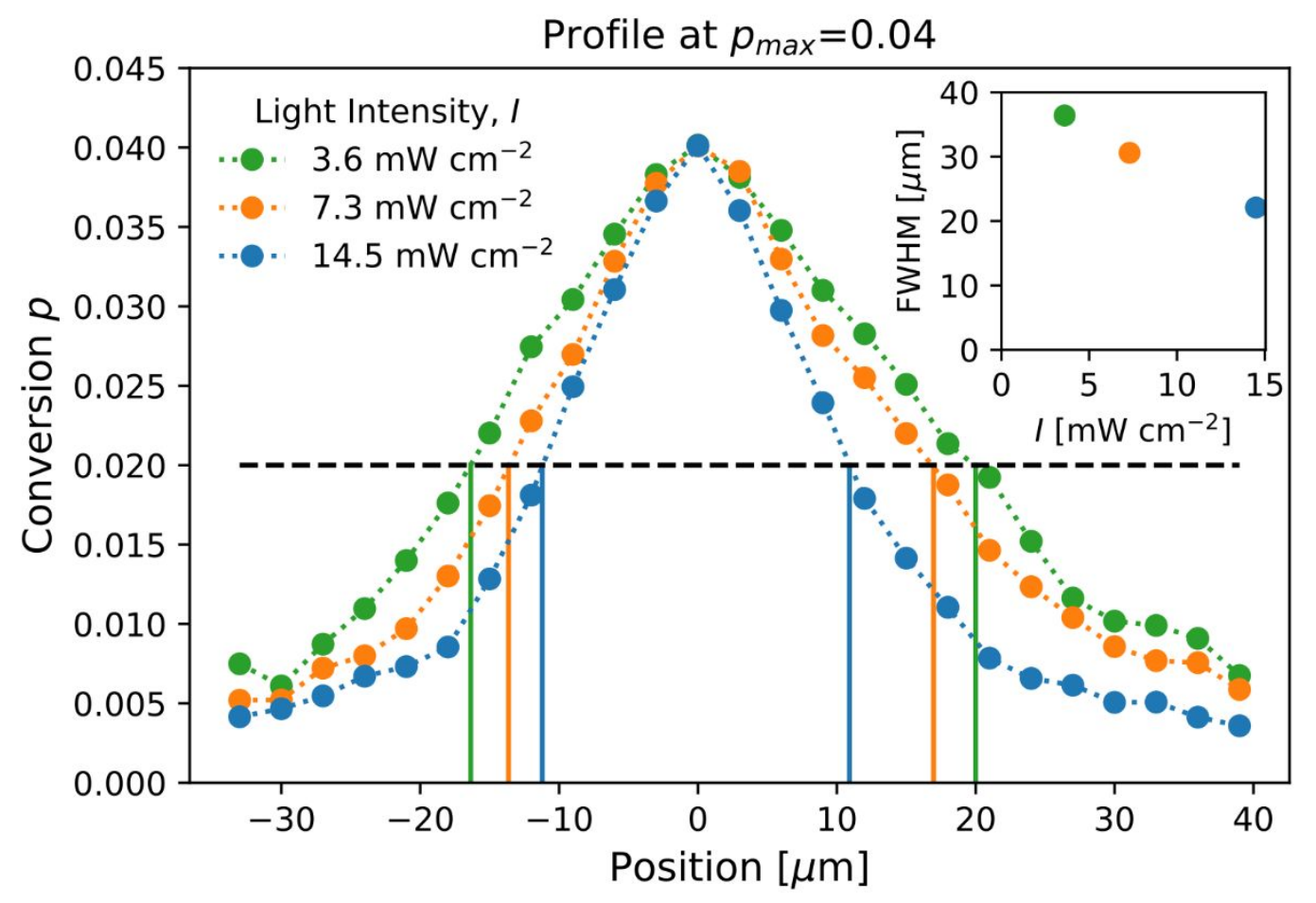

Supplemental Figure S9: Conversion profiles at equal $p_{\max }=0.04$ for different light intensities. Inset - the full width at half $\max (F W H M)$ quantified for the conversion profiles are plotted as a function of light intensity. Comparing $3.6 \mathrm{~mW} \mathrm{~cm}^{-2}$ to $14.5 \mathrm{~mW} \mathrm{~cm}^{-2}$, a $39 \%$ reduction in the FWHM is measured

a)

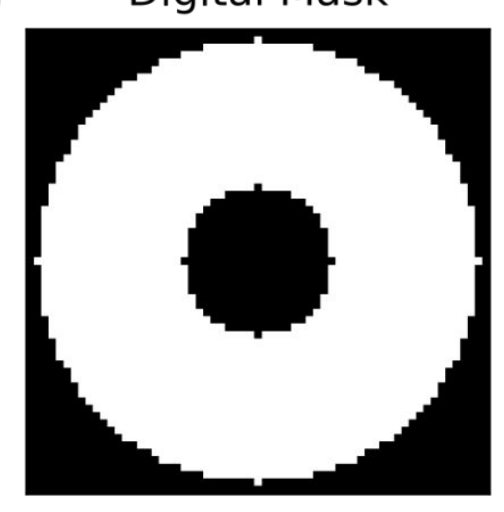

b)

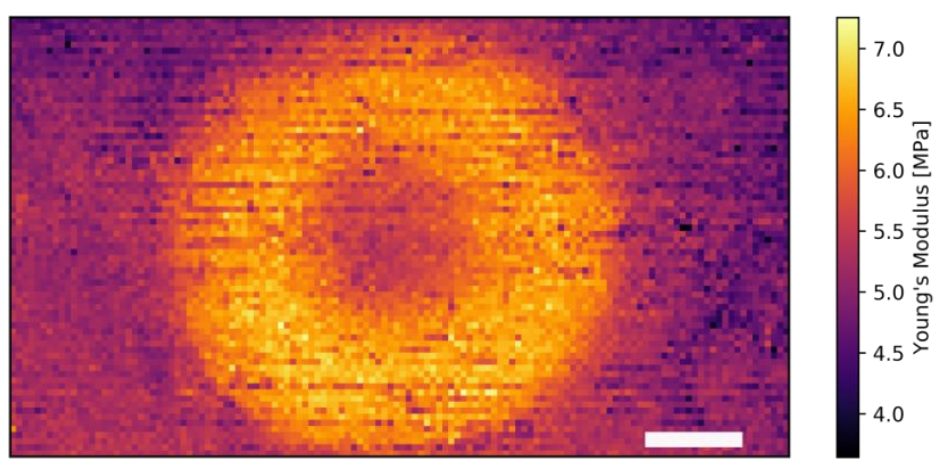

Supplemental Figure S10: Photopolymerization response in a dual-cure material shows the fidelity of the digital photomask (a) to the region of increased modulus (b). Young's modulus measurement is performed in force-volume mapping on the AFM, with a force versus distance measurement taken at each point. Scale bar $10 \mu \mathrm{m}$. 


\section{References}

[1] J. Dupré De Baubigny, M. Benzaquen, C. Mortagne, C. Devailly, S. Kosgodagan Acharige, J. Laurent, A. Steinberger, J. P. Salvetat, J. P. Aimé, T. Ondarçuhu, Phys. Rev. Fluids 2016, 1, 1.

[2] R. G. Cox, J. Fluid Mech. 1970, 44, 791. 